\title{
Stroke in COVID-19: a single-centre initial experience in a hotspot of the pandemic
}

\author{
Ivo Bach (D) , ${ }^{1}$ Pratibha Surathi, ${ }^{1}$ Nora Montealegre, ${ }^{1}$ Osama Abu-Hadid, ${ }^{1}$ \\ Sara Rubenstein, ${ }^{1}$ Sviatoslav Redko, ${ }^{1}$ Siddharth Gupta, ${ }^{1}$ Machteld Hillen, ${ }^{1}$ \\ Pratit Patel, ${ }^{2}$ Priyank Khandelwal, ${ }^{2}$ Adham Kamel ${ }^{1}$
}

To cite: Bach I, Surathi P, Montealegre $\mathrm{N}$, et al. Stroke in COVID-19: a single-centre initial experience in a hotspot of the pandemic. Stroke \& Vascular Neurology 2020;5: e000525. doi:10.1136/svn-2020-000525

Received 18 July 2020 Accepted 3 August 2020 Published Online First 24 September 2020
Check for updates

(C) Author(s) (or their employer(s)) 2020. Re-use permitted under CC BY-NC. No commercial re-use. See rights and permissions. Published by BMJ.

${ }^{1}$ Department of Neurology and Neurosciences, New Jersey Medical School, Newark, New Jersey, USA

${ }^{2}$ Department of Neurological Surgery, New Jersey Medical School, Newark, New Jersey, USA

Correspondence to Dr Ivo Bach;

Ivo.Bach@Rutgers.edu

\section{ABSTRACT}

Background COVID-19, caused by SARS-CoV-2, is a global pandemic that has been an immense burden on healthcare systems all over the world. These patients may be at higher risk for acute ischaemic stroke (AIS). We present our experience with AIS in patients with COVID-19. Methods We reviewed all patients admitted to our hospital during a 6-week period with a positive nasopharyngeal swab test for SARS-CoV-2. Among these patients, we identified AIS. We reviewed the demographics, clinical, laboratory, imaging characteristics, treatments received and outcomes of AIS in patients with COVID-19.

Results We identified 683 patients admitted with COVID-19 during the study period, of which 20 patients had AIS. Large-vessel occlusion (LV0) was noted in 11 patients (55\%). Intravenous alteplase was administered in four patients $(20 \%)$ and mechanical thrombectomy was performed in five patients (25\%). Respiratory symptoms preceded the onset of AIS in most of the patients (70\%) by 1 to 21 days. Mortality in patients with AIS was $50 \%$ compared with $26 \%$ of all COVID-19 admissions. Most of these patients died due to non-neurological causes (70\%). Three patients with AIS had clinical and imaging findings consistent with COVID-19, but were negative for multiple nasopharyngeal swab tests.

Interpretation LVO was more common in patients with AIS and COVID-19. They had more severe disease and higher mortality rates. Most of the patients had respiratory symptoms preceding AIS by days to weeks. This could explain certain patients with clinical picture of COVID-19 but negative nasopharyngeal swab tests.

\section{INTRODUCTION}

On 11 March 2020, the WHO declared COVID-19, the disease caused by SARS-CoV-2 a global pandemic. COVID-19 has placed an immense burden on healthcare systems and has had a great impact on society. There are now over 3.5 million cases worldwide, with over one million cases in the USA. ${ }^{1}$ COVID-19 has largely been described as a respiratory illness, with the most common symptoms reported as cough, shortness of breath and fever. ${ }^{23}$ Recent literature has suggested that COVID-19 is not solely a respiratory disease but has the potential to affect multiple organs. ${ }^{45}$
There is emerging evidence supporting the development of severe coagulopathies among patients with COVID-19, as demonstrated in a Dutch study by Klok et al, which showed that $31 \%$ of patients in the intensive care unit had thrombotic complications. ${ }^{6-8}$ There are also increasing reports of acute ischaemic stroke (AIS), with a reported incidence between $2.5 \%$ and $5.6 \%$ of patients with COVID-19. ${ }^{49}$ A recently published mini case series by Oxley $e t a l^{10}$ found an increase in AIS due to large-vessel occlusion (LVO) among patients aged 50 years and younger with COVID-19. Emerging theories suggest that patients may be at risk for stroke due to multiple factors, including an excessive inflammatory response, hypercytokinaemia, prothrombotic state and endothelial dysfunction secondary to depletion of angiotensinconverting enzyme 2 (ACE2). ${ }^{811}$

We present our initial experience of AIS in patients with COVID-19 in a tertiary comprehensive stroke centre located in one of the COVID-19 hotspots in the USA.

\section{METHODS}

This is a retrospective, observational study, which was conducted at University Hospital in Newark, New Jersey, a designated comprehensive stroke centre. The first patient with confirmed COVID-19 was admitted to our hospital on 15 March 2020. We reviewed all patients admitted to our hospital from 15 March 2020 through 30 April 2020. All patients with positive results for SARS-CoV-2 reverse transcriptase PCR (RT-PCR) assay of nasopharyngeal swab were included for analysis. We further identified all patients with SARS-CoV-2 who had AIS by chart review and reviewed all stroke team consults during this period.

We investigated the electronic medical records, laboratory data and imaging studies for all patients with AIS and 
laboratory-confirmed SARS-CoV-2 infection. We collected data on age, sex and risk factors for stroke, including a documented history of, or treatments for, hypertension, atrial fibrillation, diabetes mellitus, smoking, obesity, hyperlipidaemia and prior ischaemic stroke. We included chronic kidney disease, heart failure and systemic atherosclerosis in our data collection. We documented the prior use of antiplatelet agents and anticoagulants. For each patient, we recorded presenting symptoms, including respiratory, systemic and neurological symptoms. We documented the initial National Institute of Health Stroke Scale (NIHSS). We recorded the date of onset of respiratory symptoms (if present), in relation to the date of onset of AIS. Interventions, including administration of tissue plasminogen activator (tPA) and mechanical thrombectomy (MT), were reviewed for each patient. Inflammatory and coagulation markers, including platelets, international normalised ratio, D-dimer, ferritin, fibrinogen and $\mathrm{C}$ reactive protein (CRP) were collected for each patient. Laboratory values collected closest to the time of stroke onset were used in our analysis. We reviewed all neuroimaging, as well as echocardiogram reports for each patient, if available. Severity of COVID-19 infection was evaluated based on evidence of multiorgan dysfunction syndrome (MODS) and respiratory support required during hospital admission. We documented the outcomes for all patients, which included discharge to home, discharge to acute rehabilitation centre, discharge to skilled nursing facility or death.

Continuous variables, including laboratory values, are presented as means and SD for normally distributed data. Categorical variables are presented as counts and percentages. For factors determining outcomes, we calculated the $\mathrm{p}$ value using $\mathrm{Z}$ score and $\chi^{2}$ test.

\section{RESULTS}

We analysed a total of 683 patients admitted to the hospital with laboratory-confirmed COVID-19 between 15 March 2020 to 30 April 2020. Twenty patients (2.9\%) had documented AIS. We found three additional patients with large-vessel AIS, who had known exposure to COVID-19, elevated inflammatory markers and bilateral chest infiltrates suggestive of viral pneumonia. Multiple nasopharyngeal swab tests were negative for SARS-CoV-2 in these patients; therefore, they were not included in our analysis.

\section{Demographics and risk factors for patients with AIS}

The mean age of the 20 patients included in our analysis was $63 \pm 10 \cdot 7$ (range: $37-78$ ), and 14 (63\%) were men. The most common risk factors identified were hypertension in 18 patients $(90 \%)$, diabetes mellitus in $13(65 \%)$ and obesity in 10 patients $(50 \%)$. Other risk factors are summarised in table 1. All patients had at least one stroke risk factor, and nine patients $(45 \%)$ had three or more risk factors.
Table 1 Characteristics of patients with COVID-19 and AIS

\begin{tabular}{lr} 
Patient characteristics & n (\%) \\
\hline Risk factors & \\
Hypertension & $18(90)$ \\
Diabetes & $13(65)$ \\
Hyperlipidaemia & $8(40)$ \\
Obesity & $17(85)$ \\
Cancer & $3(15)$ \\
Smoking & $5(25)$ \\
Prior stroke & $2(10)$ \\
Prior atrial fibrillation & $1(5)$
\end{tabular}

\section{Stroke characteristics}

$\begin{array}{ll}\text { LVO } & 11(55)^{\star} \\ \text { M1 } & 2 \\ \text { M2 } & 3 \\ \text { A2 } & 1 \\ \text { ICA } & 1 \\ \text { Basilar } & 2 \\ \text { Vertebral } & 1 \\ \text { Large-vessel stenosis } & 5(25) \\ \text { M1 } & 4\end{array}$

Basilar

1

$\begin{array}{ll}\text { Normal CTA } & 4(20) \\ \text { CTA not done } & 1(5)\end{array}$

\section{Treatment}

$\begin{array}{cc}\text { IV tPA received } & 4(20) \\ \text { IV tPA not received } & 16(80) \\ \text { Delay in arrival } & 11\end{array}$

Transfers for endovascular procedure 3

Very low NIHSS for tPA 2

Mechanical thrombectomy $4(20) \dagger$

Angioplasty 1 (5)

\begin{tabular}{|c|c|}
\hline Cardiopathy & \\
\hline Atrial fibrillation & $2(10)$ \\
\hline New onset & 1 \\
\hline Prior history & 1 \\
\hline Heart failure & $3(15)$ \\
\hline Acute on chronic & 1 \\
\hline New onset-acute & 2 \\
\hline Left atrial enlargemen & $3(15)$ \\
\hline
\end{tabular}

or electrocardiography

\begin{tabular}{ll}
\hline Presumed stroke mechanism & \\
\hline Large artery atherosclerosis & $5(20)$ \\
\hline Cardioembolic & $2(10)$ \\
\hline Small vessel stroke & $1(5)$ \\
Arterial dissection & $1(5)$ \\
Cryptogenic & $2(10)$ \\
Incomplete work up & $9(45)$ \\
\hline
\end{tabular}

Continued 


\begin{tabular}{|c|c|}
\hline Patient characteristics & n (\%) \\
\hline \multicolumn{2}{|l|}{ Outcomes } \\
\hline Recurrent strokes & 2 \\
\hline Same arterial territory & 2 \\
\hline Haemorrhagic conversion & $5 \ddagger$ \\
\hline \multicolumn{2}{|l|}{$\begin{array}{l}\text { Characteristics of COVID-19 infection in } \\
\text { stroke patients }\end{array}$} \\
\hline \multicolumn{2}{|l|}{$\begin{array}{l}\text { Reason for testing for SARS-CoV-2 } \\
\text { infection }\end{array}$} \\
\hline Respiratory symptoms at presentation & 14 \\
\hline CXR/CTA findings & 4 \\
\hline Screening for endovascular procedure & 2 \\
\hline Intensive care admission & 6 \\
\hline \multicolumn{2}{|l|}{ Highest oxygen requirement } \\
\hline Mechanical ventilation & $\begin{array}{l}10(\mathrm{DNI} \\
\text { status - 4) }\end{array}$ \\
\hline BiPAP/high flow & 1 \\
\hline $\begin{array}{l}\text { Nasal canula/face mask/non-rebreather } \\
\text { mask }\end{array}$ & 5 \\
\hline None & 4 \\
\hline MODS & 10 \\
\hline \multicolumn{2}{|l|}{ Outcomes } \\
\hline Death & $10(50)$ \\
\hline Acute rehab & $5(25)$ \\
\hline Subacute rehab & $1(5)$ \\
\hline Home & $3(15)$ \\
\hline Hospice & $1(5)$ \\
\hline
\end{tabular}

${ }^{*}$ One patient had both LVO and high-grade stenosis and therefore was included in both categories.

†All interventions successful, except for one case of basilar thrombus with difficult access due to bilateral vertebral occlusion.

$\ddagger$ Asymptomatic HT1 and HT2 haemorrhage.

AIS, acute ischaemic stroke; BiPAP, Bilevel Positive Airway Pressure; CTA, CT angiogram; CXR, Chest X-ray; DNI, Do Not Intubate; HT, Hemorrhagic Transformation; ICA, internal carotid artery; IV, intravenous; LVO, large-vessel occlusion; MODS, multiorgan dysfunction syndrome; NIHSS, National Institute of Health Stroke Scale; tPA, tissue plasminogen activator.

\section{Stroke characteristics}

Thirteen patients were diagnosed with AIS on presentation to the emergency room, four patients were diagnosed during their hospitalisation and three patients presented to outside hospitals with AIS and were transferred for endovascular intervention. The mean NIHSS on presentation was $11.9 \pm 7.5$ (range: 2-26). LVO was seen in 11 patients $(55 \%)$, and high-grade large-vessel stenosis was seen in 5 patients (20\%), which includes one patient who had both and was therefore included in both categories. Four patients had a normal CT angiogram (CTA) and one patient did not complete a CTA before discharge (table 1). Fifty-five per cent of patients arrived outside the therapeutic window for intravenous (IV) tPA, while four patients (20\%) received IV tPA. Endovascular procedures were performed in five patients (table 1), while six LVO patients were not candidates for MT (table 1). Two patients $(10 \%)$ had recurrent strokes within 2 days of initial stroke (table 1). Five patients developed asymptomatic haemorrhagic conversion while on a single antiplatelet agent. One patient developed subarachnoid haemorrhage after internal carotid artery aneurysm rupture. This patient had not received IV tPA nor endovascular treatment but was treated with IV heparin for pulmonary embolism. One patient received IV heparin as part of a critical care protocol for elevated D-dimer. This patient did not have recurrent stroke or haemorrhage.

AIS mechanism was identified in nine patients. Large artery atherosclerosis was deemed to be responsible in five $(25 \%)$ cases, atrial fibrillation in two (10\%), small vessel in one and arterial dissection in one. One patient had known atrial fibrillation and one was newly diagnosed following AIS. Heart failure was seen in four patients, two of which were new in onset and two were acute exacerbations of chronic illness. Atrial enlargement was present in three patients, one of which was identified on echocardiogram, and two were noted on ECG. The aetiology of AIS could not be determined in 11 patients by the time of discharge.

\section{COVID-19 characteristics}

The first patient with AIS with COVID-19 was admitted on 27 March 2020, 12 days after the first admission to our hospital for SARS-CoV-2 infection. We compared the demographics and outcomes of all COVID-19 admissions and COVID-19 admissions with stroke (table 2).

Fourteen patients $(70 \%)$ had documented history of respiratory symptoms prior to AIS onset. Two patients $(10 \%)$ who initially presented with AIS developed respiratory symptoms during hospitalisation. Four patients $(20 \%)$ did not have respiratory symptoms, though one of them had bilateral lung infiltrates consistent with viral pneumonia. The onset of respiratory symptoms in patients that were symptomatic on arrival ranged from 1

Table 2 COVID-19 admissions vs patients with COVID-19 and AIS

\begin{tabular}{lll}
\hline & $\begin{array}{l}\text { All COVID-19 } \\
\text { patients (N=683) }\end{array}$ & $\begin{array}{l}\text { COVID-19 } \\
\text { patients with } \\
\text { AlN=20) }\end{array}$ \\
\hline Age (mean \pm SD) & $\begin{array}{l}61.13 \pm 15.39 \\
(20-100)\end{array}$ & $\begin{array}{l}63.05 \pm 10.7 \\
(37-78)\end{array}$ \\
\hline Male sex, \% & 58.1 & 63.16 \\
\hline Discharged (\%) & $438(64)$ & $10(50)$ \\
\hline Mortality (\%) & $177(26)$ & $10(50)$ \\
\hline Age deceased (mean $\pm S D)$ & $68.25 \pm 13.6$ & $66.4 \pm 7.38$ \\
\hline $\begin{array}{l}\text { NIHSS score, median } \pm S D \\
\text { (range) }\end{array}$ & $\cdot$ & $11.9 \pm 7.5(2-26)$ \\
\hline
\end{tabular}

AIS, acute ischaemic stroke; NIHSS, National Institute of Health Stroke Scale. 


\begin{tabular}{llll}
\hline Table 3 & \multicolumn{4}{l}{ Factors contributing to poor outcome } \\
& Death $(\mathbf{N}=10)$ & Discharged $(\mathbf{N}=10)$ & P value \\
\hline ARDS & 7 & 3 & 0.03 \\
MODS & 8 & 2 & 0.01 \\
\hline
\end{tabular}

ARDS, acquired respiratory distress syndrome; MODS, multiorgan dysfunction syndrome.

to 21 days prior to AIS onset. Three patients had undetermined onset of respiratory symptoms. The reason for testing for SARS-CoV-2 virus is presented in table 1, with $70 \%$ of patients being tested due to the presence of respiratory symptoms. Ten patients $(50 \%)$ required mechanical ventilation, though it was deferred in four cases due to 'Do not Intubate/Do not Resuscitate' orders (table 1). Acquired respiratory distress syndrome (ARDS) was seen in 10 patients $(50 \%)$, and MODS in 10 patients $(50 \%)$, and $9(45 \%)$ patients had both.

\section{Laboratory findings}

The coagulation and inflammatory markers at the time of AIS presentation are summarised in table 3 . The mean values of all inflammatory markers, including D-dimer, ferritin and CRP, were elevated (online supplementary table 1 ). The coagulation markers were normal in all patients at the time of AIS, except for one with prolonged activated partial thromboplastin time (aPTT) in the absence of therapeutic anticoagulation. The mean D-dimer could not be accurately calculated due to capping of the laboratory value at 7955 in our hospital, although $30 \%$ of our patients showed values of ' $>7955$ '.

\section{Outcomes}

Ten patients $(50 \%)$ died during hospitalisation and one was discharged to hospice. The mortality in patients with AIS and COVID-19 was significantly higher than mortality in patients with COVID-19 without stroke ( $p$ value 0.01 ). The immediate cause of death was neurological in three patients, secondary to herniation. Patients who had ARDS or MODS had poor outcomes. We also noted that patients with very elevated D-dimer had higher mortality.

\section{DISCUSSION}

To the best of our knowledge, we present the largest case series of AIS in patients with COVID-19 from a single centre in the USA. Initial data presented in Mao et al, ${ }^{4}$ from three hospitals in Wuhan, China, reported AIS in $5.6 \%$ of 214 patients with COVID-19. The incidence of AIS among our hospitalised patients with COVID-19 is 2.9\%, which is similar to the $2.5 \%$ of 388 patients reported in Lodigiani et $a l^{9}$ from Italy. The mean age of patients with AIS was 63 years, which approximates the mean age of patients with stroke(65 years) in our hospital over the past 3 years. Oxley et $a l^{10}$ described an increased incidence of LVO stroke in patients with COVID-19 younger than 50 years in a New York City hospital system. Our cohort includes three patients under 50 years who presented with LVO.
Almost all patients had multiple risk factors for stroke including old age, obesity, hypertension, diabetes, atrial fibrillation, hyperlipidaemia, cancer or prior strokes. It has been proposed that many of these conditions are associated with increased severity and mortality in COVID-19. ${ }^{12} 13$ Fifty-five per cent of our patients had LVO compared with the 27\%-37\% previously reported. ${ }^{14} 15$ Multiple mechanisms regarding SARS-CoV-2 as a trigger for stroke have been proposed. Such mechanisms include an imbalance between angiotensin II and angiotensin 1-7 via ACE2 sequestration producing a hypercoagulable state, cytokine release syndrome inducing plaque rupture, as well as direct and indirect cardiac effects. ${ }^{16-24}$ Given the increased incidence of LVO without intracranial atherosclerosis, we entertain the theory of cardioembolic causes including paroxysmal atrial fibrillation triggered by the infection. Ten per cent of our patients had recurrent strokes during the same hospitalisation compared with the $0.8 \%$ previously reported. ${ }^{25}$ An opinion by Elkind ${ }^{26}$ describes the need to differentiate between stroke risk factors and stroke triggers. Based on our preliminary findings, we hypothesise that infection with SARS-CoV-2 can potentially trigger hypercoagulable state, which can lead to AIS in a person with stroke risk factors.

In our analysis, $85 \%$ of patients had either respiratory symptoms or imaging findings consistent with viral pneumonia. While symptomatology varied, 70\% demonstrated respiratory symptoms at the time of AIS. We postulate that AIS may be a late complication of COVID-19, lagging behind respiratory symptoms by days to weeks. Mao et at suggested that most neurological symptoms in patients with COVID-19 present early except AIS and altered mental status, which are late presentations. As far as we know, this is the first study elucidating the timeline of respiratory symptoms in relation to AIS onset. It can be inferred that the timeline for AIS in COVID-19 may depend on stroke mechanism.

We would like to bring attention to patients with typical clinical characteristics of COVID-19, including findings on lung imaging and inflammatory markers, who presented with AIS with multiple negative nasopharyngeal swab tests for SARS-CoV-2. In these patients, the onset of respiratory symptoms preceded stroke symptoms by as many as 3 weeks, while the peak positivity for nasopharyngeal swab test is thought to be 1 to 2 weeks after symptom onset. As this pandemic continues to progress, we should consider using additional confirmatory testing, such as RT-PCR testing from other sources or antibody testing to extend the window of confirmatory testing. ${ }^{27}$ The mortality in all patients with COVID-19 admitted during the study time period in our hospital was $26 \%$, which is similar to $24.5 \%$ mortality reported among 5700 patients with COVID-19 hospitalised in New York City. ${ }^{28}$ A study from Wuhan reported $38 \%$ mortality among patients with COVID-19 who developed stroke. ${ }^{4}$ The mortality among our patients with AIS was $50 \%$. In our hospital, ARDS, MODS and elevated D-dimer were independently associated with higher mortality in patients with AIS. The poor 
outcome of patients with AIS may be caused by the presence of underlying risk factors such as diabetes, hypertension, cardiovascular disease and male sex, which are independently known to be associated with increased risk of death from COVID-19 infection. ${ }^{1329}$

A 39\% decrease in stroke imaging was noted after the announcement of the first COVID-19-related death in the USA. $^{30}$ Approximately half of our patients were out of the window for therapeutic intervention, which may have contributed to a poorer outcome. Fear of contracting COVID-19 may have prevented them from seeking care in a timely manner. ${ }^{10}$

\section{Limitations}

Limitations of our study are small sample size and incomplete stroke workup in some patients. Due to the pandemic, there was decreased availability of diagnostic testing, such as echocardiogram and lower extremity Doppler. In addition, we recognise that prevalence of stroke may be underestimated in patients receiving critical care due to limited histories and bedside examinations, haemodynamic instability preventing neuroimaging and paralytic use. Possibly inaccuracies of the information extracted from medical records may have been an additional limitation, which is inherent in retrospective studies.

\section{CONCLUSION}

Higher mortality and severe disease were noted in our patients with AIS and COVID-19 compared with patients with COVID-19 without AIS. Factors contributing to mortality include severe ARDS and possibly an excessive inflammatory response. Although stroke seems to occur in almost all stages of the disease, it is most often seen after the first week of illness or later. This could explain why some patients who presented with stroke and were highly suspected to have a COVID-19 infection tested negative after multiple nasopharyngeal swabs. Larger studies are needed to prove the association of COVID-19 and AIS and to identify the mechanisms causing thromboembolic phenomenon in these patients.

\section{Twitter Ivo Bach @Ivobach}

Contributors IB and NM contributed to study concept and design, data collection, interpretation of data, literature search, drafting of manuscript, critical revision and final approval. PS contributed to study concept and design, data collection, literature search, drafting of manuscript, analysis and interpretation of data, critical revision and final approval. OA-H contributed to study design, literature search, drafting of manuscript, analysis and interpretation of data and final approval.SRubenstein contributed to data collection, literature search, interpretation of data, drafting of manuscript, critical revision and final approval. SRedko contributed to study design, data collection, interpretation of data and final approval. SG contributed to data collection and critical revision. MH contributed to critical revision, interpretation of data and final approval. PP contributed to critical revision, literature search, interpretation of data and final approval. PK (CoGuarantor) contributed to study concept, critical revision, interpretation of data and final approval. AK (Co-Guarantor/PI) contributed to study concept, critical revision, interpretation of data and final approval.

Funding The authors have not declared a specific grant for this research from any funding agency in the public, commercial or not-for-profit sectors.
Competing interests None declared.

Patient consent for publication Not required.

Ethics approval This study was approved by the institutional review board of Rutgers University.

Provenance and peer review Not commissioned; externally peer reviewed. Data availability statement All data relevant to the study are included in the article or uploaded as supplementary information. All relevant data is included in the article or tables. Data is not publicly available at this time.

Open access This is an open access article distributed in accordance with the Creative Commons Attribution Non Commercial (CC BY-NC 4.0) license, which permits others to distribute, remix, adapt, build upon this work non-commercially, and license their derivative works on different terms, provided the original work is properly cited, appropriate credit is given, any changes made indicated, and the use is non-commercial. See: http://creativecommons.org/licenses/by-nc/4.0/.

ORCID iD

Ivo Bach http://orcid.org/0000-0003-2215-1240

\section{REFERENCES}

1 Organization WH. Coronvirus disease (COVID-19): situation report - 109, 2020. Available: https://www.who.int/docs/default-source/ coronaviruse/situation-reports/20200508covid-19-sitrep-109.pdf? sfvrsn=68f2c632_6 [Accessed 9 May 2020].

2 Guan WJ, ZY N, Hu Y, et al. Clinical characteristics of coronavirus disease 2019 in China. N Engl J Med 2020:NEJMoa2002032.

3 Huang $\mathrm{C}$, Wang $\mathrm{Y}, \mathrm{Li} \mathrm{X}$, et al. Clinical features of patients infected with 2019 novel coronavirus in Wuhan, China. Lancet 2020;395:497-506

4 Mao L, Jin H, Wang M, et al. Neurologic manifestations of hospitalized patients with coronavirus disease 2019 in Wuhan, China. JAMA Neurol 2020;77:683-690.

5 Terpos E, Ntanasis-Stathopoulos I, Elalamy I, et al. Hematological findings and complications of COVID-19. Am J Hematol 2020;95:834-47.

6 Tang N, Li D, Wang X, et al. Abnormal coagulation parameters are associated with poor prognosis in patients with novel coronavirus pneumonia. J Thromb Haemost 2020;18:844-7.

7 Spiezia L, Boscolo A, Poletto F, et al. COVID-19-related severe hypercoagulability in patients admitted to intensive care unit for acute respiratory failure. Thromb Haemost 2020;120:998-1000.

8 Klok FA, Kruip MJHA, van der Meer NJM, et al. Incidence of thrombotic complications in critically ill ICU patients with COVID-19. Thromb Res 2020;191:145-7.

9 Lodigiani C, lapichino G, Carenzo L, et al. Venous and arterial thromboembolic complications in COVID-19 patients admitted to an academic hospital in Milan, Italy. Thromb Res 2020;191:9-14.

10 Oxley TJ, Mocco J, Majidi S, et al. Large-vessel stroke as a presenting feature of Covid-19 in the young. N Engl J Med 2020;382:e60.

11 Hess DC, Eldahshan W, Rutkowski E. COVID-19-related stroke. Trans/ Stroke Res 2020.

12 Zhou F, Yu T, Du R, et al. Clinical course and risk factors for mortality of adult inpatients with COVID-19 in Wuhan, China: a retrospective cohort study. Lancet 2020;395:1054-62.

13 Wu C, Chen X, Cai Y, et al. Risk factors associated with acute respiratory distress syndrome and death in patients with coronavirus disease 2019 pneumonia in Wuhan, China. JAMA Intern Med 2020;180:934-943.

14 Malhotra K, Gornbein J, Saver JL. Ischemic strokes due to largevessel occlusions contribute disproportionately to stroke-related dependence and death: a review. Front Neurol 2017;8:651.

15 Zaidat OO, Lazzaro M, McGinley E, et al. Demand-supply of neurointerventionalists for endovascular ischemic stroke therapy. Neurology 2012;79:S35-41.

16 Poor HD, Ventetuolo CE, Tolbert T, et al. COVID-19 critical illness pathophysiology driven by diffuse pulmonary thrombi and pulmonary endothelial dysfunction responsive to thrombolysis. medRxiv 2020;10:e44.

17 Magro C, Mulvey JJ, Berlin D, et al. Complement associated microvascular injury and thrombosis in the pathogenesis of severe COVID-19 infection: a report of five cases. Trans/ Res 2020;220:1-13.

18 South AM, Diz DI, Chappell MC. COVID-19, ACE2, and the cardiovascular consequences. Am J Physiol Heart Circ Physiol 2020;318:H1084-90.

19 Mehta P, McAuley DF, Brown M, et al. COVID-19: consider cytokine storm syndromes and immunosuppression. Lancet 2020;395:1033-4. 
20 Aksu K, Donmez A, Keser G. Inflammation-induced thrombosis: mechanisms, disease associations and management. Curr Pharm Des 2012;18:1478-93.

21 Hansson GK, Libby P, Tabas I. Inflammation and plaque vulnerability. J Intern Med 2015;278:483-93.

22 Quillard T, Franck G, Mawson T, et al. Mechanisms of erosion of atherosclerotic plaques. Curr Opin Lipidol 2017;28:434-41.

23 Fried JA, Ramasubbu K, Bhatt R, et al. The variety of cardiovascular presentations of COVID-19. Circulation 2020;141:1930-6.

24 Hadi HA, Alsheikh-Ali AA, Mahmeed WA, et al. Inflammatory cytokines and atrial fibrillation: current and prospective views. $J$ Inflamm Res 2010;3:75-97.

25 Erdur H, Scheitz JF, Ebinger M, et al. In-hospital stroke recurrence and stroke after transient ischemic attack: frequency and risk factors. Stroke 2015;46:1031-7.
26 Elkind MSV. Why now? moving from stroke risk factors to stroke triggers. Curr Opin Neurol 2007;20:51-7.

27 Sethuraman N, Jeremiah SS, Ryo A. Interpreting diagnostic tests for SARS-CoV-2. JAMA 2020. doi:10.1001/jama.2020.8259. [Epub ahead of print: 06 May 2020].

28 Richardson S, Hirsch JS, Narasimhan M, et al. Presenting characteristics, comorbidities, and outcomes among 5700 patients hospitalized with COVID-19 in the new York City area. JAMA 2020. doi:10.1001/jama.2020.6775. [Epub ahead of print: 22 Apr 2020].

29 Chen T, Wu D, Chen H, et al. Clinical characteristics of 113 deceased patients with coronavirus disease 2019: retrospective study. BMJ 2020;368:m1091.

30 Kansagra AP, Goyal MS, Hamilton S, et al. Collateral effect of Covid-19 on stroke evaluation in the United States. N Engl J Med 2020;383:400-1. 